\title{
A new species of Simulium (Nevermannia) from northern Thailand (Diptera: Simuliidae)
}

\author{
Hiroyuki TAKAOKA ${ }^{1)}$ and Wej CHOоCHOTE ${ }^{2)}$ \\ 1) Department of Infectious Disease Control, Faculty of Medicine, \\ Oita University, Yufu City, Oita, 879-5593 Japan \\ ${ }^{2)}$ Department of Parasitology, Faculty of Medicine, Chiang Mai University, \\ Chiang Mai, 50200 Thailand
}

(Received: 13 December 2005; Accepted: 23 January 2006)

\begin{abstract}
Simulium (Nevermannia) fangense sp. nov. is described based on the female, male, pupal and larval specimens collected from northern Thailand. This species is assigned to the feuerborni species-group of the subgenus Nevermannia, and is very similar to $S$. (N.) sasai (Rubtsov), but is distinguished by the medium brown scutum of the female with three longitudinal vittae, and the greater number of secondary lobules of the rectal organ in the larva.
\end{abstract}

Key words: Simulium, black fly, Simuliidae, Thailand, Nevermannia

The feuerborni species-group within the subgenus Simulium (Nevermannia) Enderlein redefined by Takaoka (2003) is represented in Thailand by three species, $S$. (N.) feuerborni Edwards, which was originally described from Java (Edwards, 1934) and later recorded from Peninsular Malaysia (Takaoka and Davies, 1995) and Thailand (Kuvangkadilok et al., 1999), S. (N.) fruticosum and $S$. (N.) chiangklangense, both described from northern Thailand (Takaoka and Choochote, 2005). We collected one more species of the feuerborni species-group, which is similar to $S$. $(N$.) sasai (Rubtsov) from Japan (Sato et al., 2005). It is here described as a new species based on the female, male, pupal and mature larval specimens.

The terms for morphological features used here follow those of Takaoka (2003). Holotype and paratype specimens of the new species are deposited at the Department of Infectious Disease Control, Oita University, Oita, Japan.

\section{Simulium (Nevermannia) fangense sp. nov.}

DESCRIPTION. Female. Body length 2.6$3.2 \mathrm{~mm}$. Head. Narrower than thorax. Frons brownish-black, thinly whitish-grey pruinose, densely covered with whitish-yellow recumbent hairs interspersed with several dark brown longer and stouter hairs along each lateral margin. Frontal ratio $1.6-1.7: 1.0: 2.2-2.5$. Frons-head ratio $1.0: 4.6-4.8$. Fronto-ocular area (Fig. 1A) well developed, triangular, directed somewhat upward. Clypeus brownish-black, whitish-grey pruinose, densely covered with whitish-yellow recumbent hairs (except portion near upper margin bare) intermixed with several dark longer and stouter hairs on each side. Labrum about 0.92 times as long as clypeus. Antenna composed of $2+9$ segments, brownish-black, except scape, pedicel, and base of 1st flagellar segment yellow; 1 st flagellar segment nearly as long as wide and 1.8-1.9 times as long as 2nd one. Maxillary palp consisting of 5 segments, blackish, proportional lengths of $3 \mathrm{rd}, 4 \mathrm{th}$, and 5 th segments 1.0 : $0.9: 1.7$; 3rd segment (Fig. 1B) much enlarged, with sensory vesicle elongate, about 0.6 times as long as 3rd segment, with medium-sized opening. Maxillary lacinia with 6-8 inner and 
14 or 15 outer teeth. Mandible with 22 or 23 inner teeth and lacking outer teeth though 1 outer tooth near apex present in 1 female. Cibarium smooth on posterodorsal margin, with pair of well sclerotized cornuae directed anterolaterally. Thorax. Scutum medium brown except anterolateral calli ocherous and along lateral margins and part of prescutellar area dark brown, with 3 dark brown narrow longitudinal vittae (1 medial, 2 submedial), slightly shiny and thinly whitish-grey pruinose with 3 dark narrow non-pruinose longitudinal vittae (1 medial, 2 submedial) when illuminated at certain angle of light, and densely covered with whitish-yellow recumbent hairs intermixed with several dark brown upright hairs on prescutellar area. Scutellum ocherous to light brown, with several dark brown upright hairs as well as whitish-yellow shorter hairs. Postnotum dark brown, whitishgrey pruinose, and bare. Lateral surface of thorax dark brown, slightly shiny at certain angle of light, thinly whitish-grey pruinose, and bare. Pleural membrane bare. Katepisternum longer than deep, dark brown, and bare. Furcasternum with distinct apodeme directed downwards on each arm. Legs. Foreleg: coxa and trochanter yellow; femur yellow with apical cap medium brown; tibia dark brown with apical cap black; tarsus black; basitarsus slender, slightly dilated, 8.0 times as long as its greatest width. Midleg: coxa yellow to light brown except posterior surface brownish-black; trochanter yellow; femur yellow with apical cap medium to dark brown; tibia medium brown with apical cap brownishblack; tarsus brownish-black to black. Hind leg: coxa yellow to light brown; trochanter yellow; femur yellow with apical cap dark brown; tibia medium brown with base yellow and apical cap brownish-black; tarsus brownish-black with a little more than basal $1 / 2$ of basitarsus light to medium brown; basitarsus (Fig. 1C) nearly parallel-sided from base to middle, then slightly narrowed toward apex, 6.26-6.45 times as long as its greatest width; calcipala well developed, nearly as long as wide; pedisulcus well developed. Claw (Fig. 1D) with large basal tooth 0.50 times as long as claw. Wing. Length $2.7-2.9 \mathrm{~mm}$. Costa with 2 parallel rows of dark short spines as well as dark hairs except subbasal portion of costa near humeral cross vein with patch of whitish hairs. Subcosta with dark hairs except near apex bare. Basal portion of radius fully haired; $\mathrm{R}_{1}$ with dark spinules and hairs; $\mathrm{R}_{2}$ with dark hairs. Hair tuft on stem vein dark brown. Basal cell absent. Abdomen. Basal scale light brown, with fringe of whitish-yellow long hairs. Dorsal surface of abdomen brownishblack except segment 2 light brown, densely covered with whitish-yellow short hairs interspersed with dark ones; tergites 6-8 slightly shiny when illuminated at certain angle of light; ventral surface of segment 7 with large sternal plate medially. Genitalia. Sternite 8 (Fig. 1E) wide, bare medially but furnished with 25-32 short and long hairs on each side. Ovipositor valves (Fig. 1E) triangular, thin, membranous except inner margin narrowly sclerotized, densely covered with microsetae interspersed with 3-6 short hairs; inner margins gently sinuous and narrowly or moderately separated medially from each other. Genital fork (Fig. 1F) of inverted Y-form, with well sclerotized stem and wide arms; each arm with wide round lobe-like projection directed medioposteriorly and prominent projection directed forward. Paraproct in ventral view (Fig. 1G) of usual form, about 1.3 times as long as its greatest width; anteromedial surface moderately sclerotized, with 6-8 sensilla; paraproct in lateral view (Fig. $1 \mathrm{H}$ ) about 0.9 times as long as its greatest width, protruding ventrally to some extent beyond ventral margin of cercus. Cercus in lateral view (Fig. 1 $\mathrm{H}, \mathrm{I})$ rounded posteriorly or subtriangular, 0.51-0.61 times as long as basal width. Spermatheca (Fig. 1J) nearly globular, 1.1 times as long as its greatest width, strongly sclerotized except small area around juncture to duct and duct itself unsclerotized, with distinct reticulate surface pattern and without internal setae; main spermathecal duct narrow, about 0.75 times as wide as both accessory ducts.

Male. Body length $3.3-3.5 \mathrm{~mm}$. Head. As wide as thorax. Holoptic; upper eye consisting of large facets in 21 vertical columns and 21 horizontal rows. Clypeus black, not shiny, whitish pruinose, moderately covered with pale and dark simple hairs except medial portion bare longitudinally. Antenna composed of $2+9$ segments, light brown to brownish-black except basal $1 / 3$ of 1 st flagellar segment yellow; 1st flagellar segment elongate, about 2.5 times as long as 2nd one. Maxillary palp dark brown, composed of 5 segments, propor- 


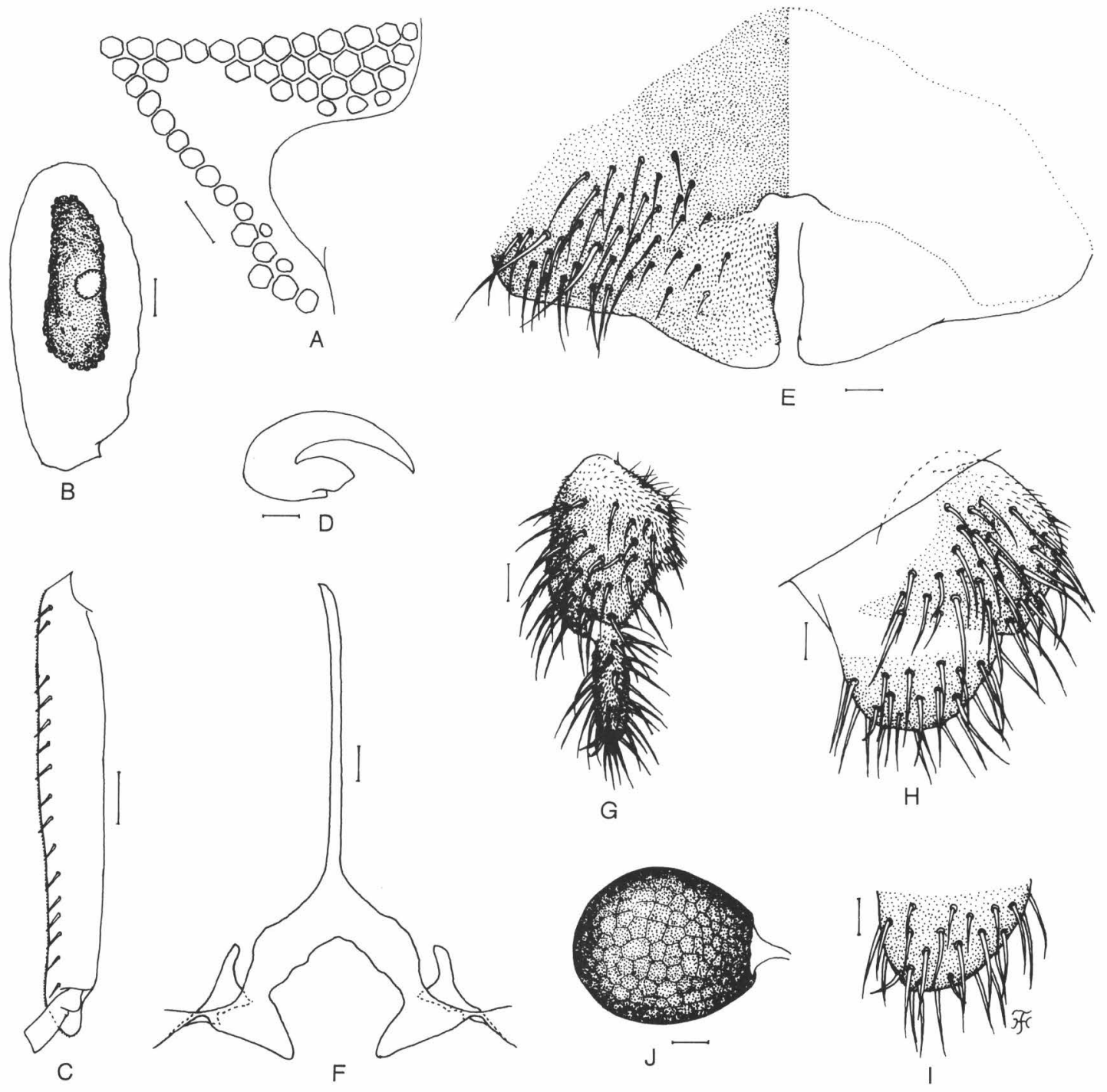

Fig. 1. Female of Simulium (Nevermannia) fangense sp. nov. A, fronto-ocular area (right side); B, 3rd segment of maxillary palp with sensory vesicle (right side, front view); C, basitarsus and 2nd tarsal segment of hind leg (left side, outer view); D, claw; E, 8th sternite and ovipositor valves in situ (ventral view); F, genital fork (ventral view); G and H, paraprocts and cerci (right side; G, ventral view; $\mathrm{H}$, lateral view); I, cercus (right side, lateral view); J, spermatheca. Scale bars. $0.1 \mathrm{~mm}$ for C; $0.04 \mathrm{~mm}$ for A; $0.02 \mathrm{~mm}$ for $\mathrm{B}$ and $\mathrm{E}-\mathrm{J} ; 0.01 \mathrm{~mm}$ for $\mathrm{D}$.

tional lengths of $3 \mathrm{rd}, 4 \mathrm{th}$, and 5 th segments $1.0: 1.1: 1.9$; 3rd segment (Fig. 2A) of moderate size; sensory vesicle (Fig. 2A) small, globular, 0.15 times as long as 3rd segment. Thorax. Scutum brownish-black, slightly shiny and thinly whitish-grey pruinose with 3 dark narrow non-pruinose longitudinal vittae (1 medial, 2 submedial) when illuminated at certain angle of light, and densely covered with golden-yellow recumbent hairs interspersed with several black upright hairs on prescutellar area. Scutellum medium brown, with many black upright long hairs as well as goldenyellow shorter hairs. Postnotum brownishblack, whitish-grey pruinose, and bare. Lateral surface of thorax brownish-black, whitishgrey pruinose. Pleural membrane bare. Katepisternum longer than deep, dark brown, and bare. Legs. Foreleg: coxa yellow; trochanter dark yellow to light brown; femur greyish- 


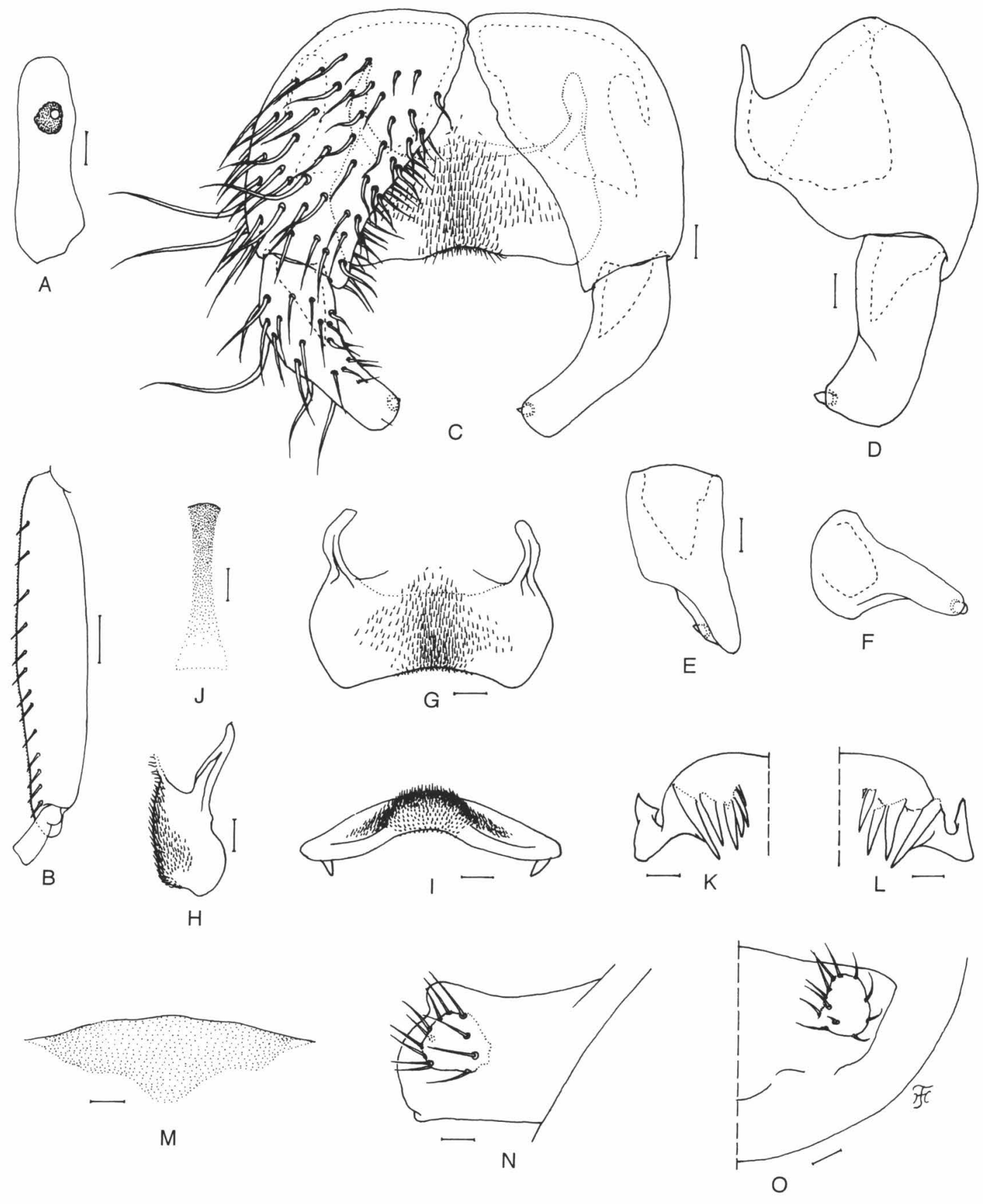

Fig. 2. Male of Simulium (Nevermannia) fangense sp. nov. A, 3rd segment of maxillary palp with sensory vesicle (right side, front view); B, basitarsus and 2nd tarsal segment of hind leg (left side, outer view); C, coxites, styles and ventral plate in situ (ventral view); D, coxite and style (right side, lateral view); E and F, styles (right side; E, ventrolateral view; F, end view); G-I, ventral plates (G, ventral view; H, lateral view; I, end view); J, median sclerite (ventral view); K, paramere with 6 hooks (right side; end view); L, paramere with 5 hooks (left side; end view); M, dorsal plate; $\mathrm{N}$ and O, 10th abdominal segments with cercus (left side; N, lateral view; O, end view). Scale bars. $0.1 \mathrm{~mm}$ for B; $0.02 \mathrm{~mm}$ for A and $\mathrm{C}-\mathrm{O}$. 
yellow with apical cap dark brown; tibia brownish-black though median large area on outer surface dark brown; tarsus entirely brownish-black; basitarsus slender, cylindrical, 9.0-9.2 times as long as its greatest width. Midleg: coxa brownish-black; trochanter yellow; femur greyish-yellow with apical cap dark brown; tibia light to medium brown with minute base yellow and apical cap brownishblack; tarsus brownish-black. Hind leg: coxa dark yellow; trochanter yellow; femur greyishyellow with apical cap dark brown; tibia light to dark brown with minute base yellow and apical cap brownish-black; tarsus dark brown to brownish-black except basal $3 / 5$ of basitarsus medium brown; basitarsus (Fig. 2B) enlarged, spindle-shaped, 4.8-5.6 times as long as its greatest width, and $0.77-0.90$ times and $0.77-0.84$ times as wide as greatest widths of hind tibia and femur, respectively; calcipala well developed, nearly as long as or slightly shorter than basal width, and pedisulcus well developed. All femora densely covered with dark hairs interspersed with golden-yellow hairs on outer surface. Fore tibia moderately covered with golden-yellow hairs on outer surface of basal $2 / 3$ of shaft; mid and hind tibiae densely covered with dark hairs intermixed with golden-yellow hairs on outer surface of basal $1 / 3$ or a little more of shaft. Wing. As in female except subcosta bare; length 2.5-2.8 $\mathrm{mm}$. Abdomen. Basal scale dark brown to brownish-black, with fringe of dark long hairs. Dorsal surfaces of abdominal segments entirely dark brown to brownish-black except basal $1 / 4$ to $1 / 2$ of segment 2 yellowish-white to yellow, not shiny except tergite of segment 2 shiny when illuminated at certain angle of light, and moderately covered with light brown to black simple hairs. Genitalia. Coxite in ventral view (Fig. 2C) rectangular, about 1.9 times as long as its greatest width. Style in ventral view (Fig. 2C) short, about 0.7 times as long as coxite, bent inwardly, with stout spine apically; style in lateral view (Fig. 2D) nearly parallel-sided; style in ventrolateral view (Fig. 2E) broad, nearly parallel-sided from base to a little beyond middle, then abruptly tapered apically; style in end view (Fig. 2F) tapered inwards. Ventral plate in ventral view (Fig. 2C, G) lamellate, much shorter than wide, well sclerotized, with shallow to medium-deep concavity medially on posterior margin, and moderately covered with fine short setae on ventral surface except lateral portions bare; arm (Fig. 2 C, G) of moderate length, slender, straight, directed anteriorly or curved inwardly; ventral plate in lateral view (Fig. $2 \mathrm{H}$ ) not produced ventrally; ventral plate in end view (Fig. 2I) with fine short setae centrally on posterior surface. Median sclerite (Fig. 2J) simple, clubshaped, narrow, widened near apex. Paramere (Fig. 2K, L) with 5 or 6 hooks decreasing in length toward apex (smallest hook often very weakly developed and much smaller than preceding one, therefore there seem to be 4 or 5 distinct long hooks and 1 very short one). Aedeagal membrane moderately covered with minute spines mostly in comb-like groups; dorsal plate (Fig. 2M) thin, with medial portion protruding posteriorly, appearing $\mathrm{T}$-shaped. Ventral surface of 10th segment without any distinct hairs near each posterolateral corner. Cercus (Fig. 2N, O) small, rounded and encircled by $8-13$ simple hairs.

Pupa. Body length $2.8-3.5 \mathrm{~mm}$. Head. Integument medium brown, moderately or densely covered with tubercles of various shapes; antennal sheaths bare; frons with 2 medium-long slender simple trichomes on each side; face with 1 long somewhat stout simple or bifid trichome with coiled apex (about twice as long as frontal trichomes) on each side. Thorax. Integument medium brown, moderately covered with round tubercles, with 3 long slender simple trichomes with coiled apex mediodorsally, 2 slender simple trichomes (1 long and 1 medium-long) mediolaterally, 1 medium-long slender simple trichome posterolaterally, and 3 short slender simple trichomes ventrolaterally, on each side. Gill with 6 long thread-like slender filaments; branching at base somewhat variable by pupae and also by gills of the same pupae: in 9 pupae examined, 6 pupae with $2+1+1+2$ filaments from dorsal to ventral on both sides ( 2 middle individual filaments lying outwardly) (Fig. 3A), 1 pupa with $2+1+1+2$ filaments ( 2 middle individual filaments lying outwardly) (Fig. 3B) on left side but with $2+2+1+1$ filaments (middle pair lying inwardly) (Fig. 3C) on right side; 1 pupa with $2+1+1+2$ filaments on both sides (1 of 2 middle filaments lying outwardly and 1 inwardly) (Fig. 3D), and 1 pupa with $3+$ $1+2$ filaments on both sides ( 1 middle individual filament lying outwardly) (Fig. 3E), all pupae with short common basal stalk; dorsal pair of filaments with very short to short stalk, 

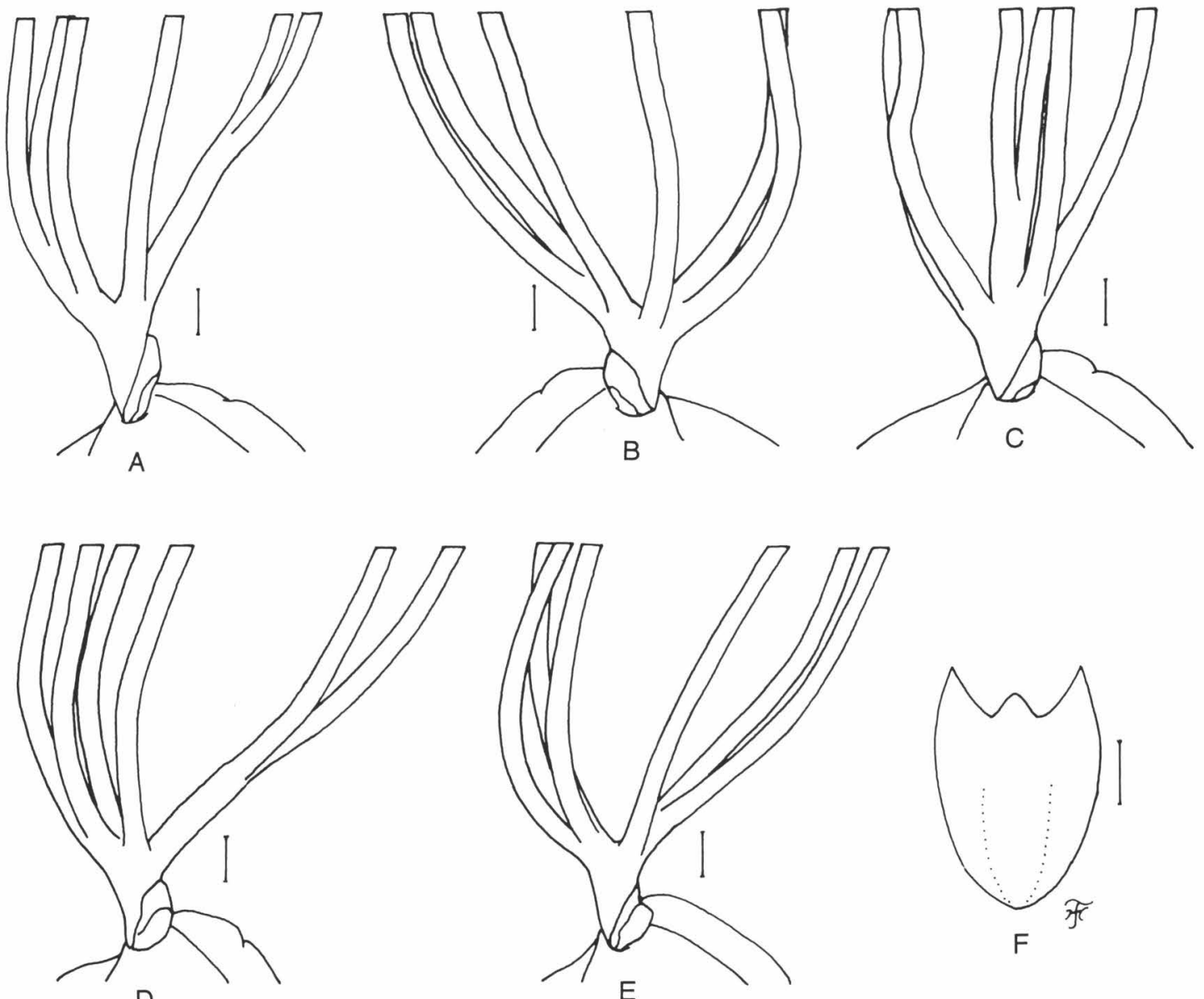

Fig. 3. Pupa of Simulium (Nevermannia) fangense sp. nov. A-E, basal portions of gill filaments showing variations in branching of gill filaments and in length of stalk of the ventral pair (A and C-E, right side; B, left side); F, cocoon (dorsal view). Scale bars. $1.0 \mathrm{~mm}$ for F; $0.1 \mathrm{~mm}$ for A-E.

and ventral pair with short to medium-long stalk; all filaments tapered toward tip, extending anteriorly, subequal in length $(5.2-5.8 \mathrm{~mm}$ long) to one another except lower 2 filaments (4.0-5.0 mm long) slightly shorter than others; cuticular surface with distinct annular ridges and furrows, and densely covered with minute tubercles of different sizes (larger ones on ridges and smaller ones on interridges). Abdomen. Dorsally, all segments densely and elaborately covered with minute tubercles; segments 1 and 2 medium to dark brown; segment 1 with 1 medium-long simple seta (though additional 1 short simple seta present in 1 pupa) on each side; segment 2 with 1 medium-long slender simple seta and 5 short spinous setae on each side; segments 3 and 4 each with 4 hooks and 1 short spinous seta on each side; segment 5 bare; segments $6-8$ each with spinecombs directed backward in transverse row and comb-like groups of minute spines on each side; segment 9 with pair of distinct horn-shaped terminal hooks curved posteroinwardly as well as comb-like groups of minute spines. Ventrally, segments 3-8 with comblike groups of minute spines; segment 4 with 4 short simple slender setae, 2 of which somewhat stouter than 2 others, on each side; segment 5 with pair of bifid hooks submedially and a few short slender setae on each side; segments 6 and 7 each with pair of 1 bifid inner and 1 simple outer hooks (though outer hook on segment 7 not or weakly to moderately developed and much smaller than that on segment 6) and a few slender setae on each side. Cocoon (Fig. 3F). Simple, wall-pocket-shaped, 


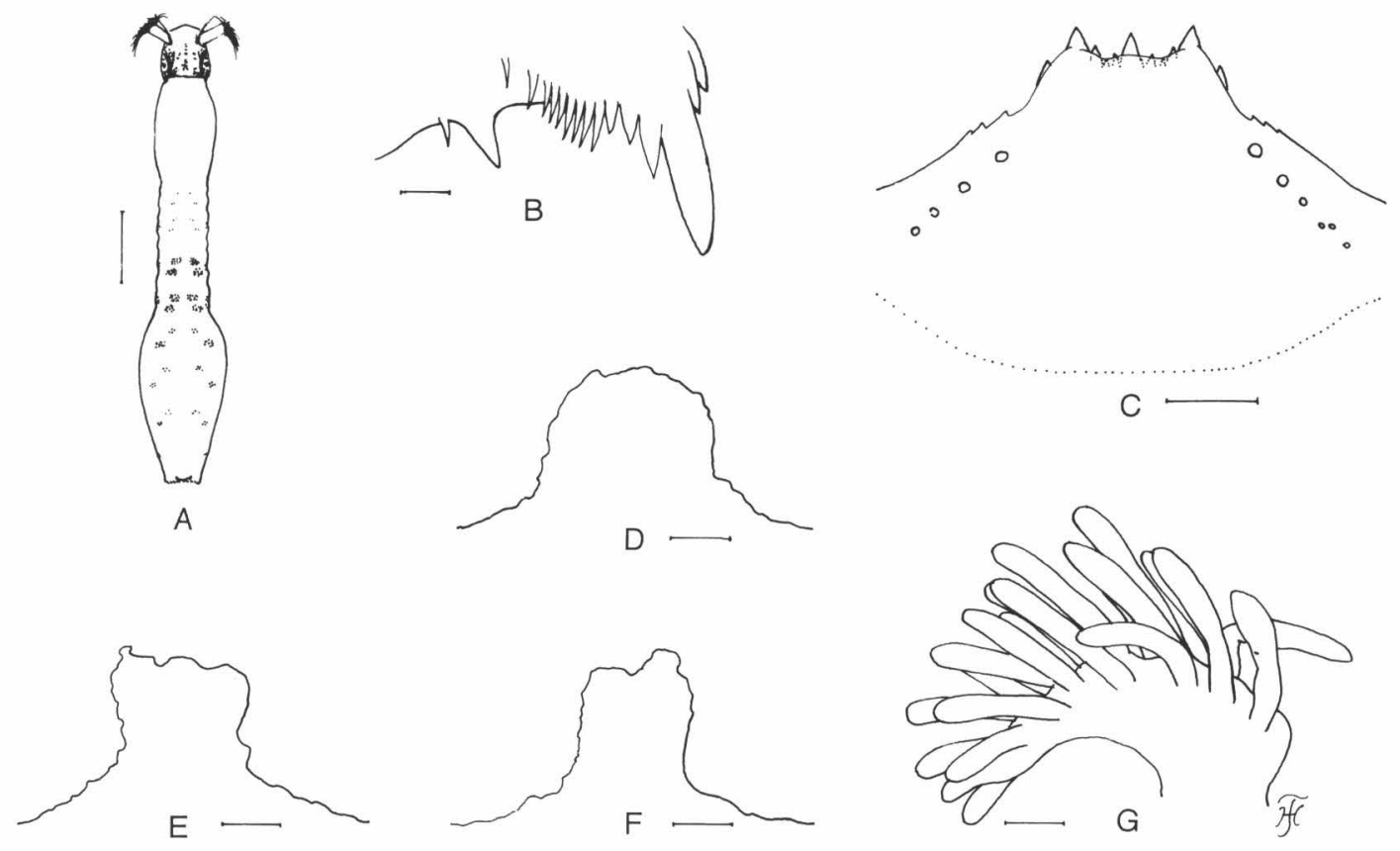

Fig. 4. Mature larva of Simulium (Nevermannia) fangense sp. nov. A, whole body showing dorsal color markings on the abdomen (dorsal view); B, apical portion of mandible; C, hypostoma; D-F, postgenal clefts of various forms; G, lobe of rectal organ with 20 finger-like secondary lobules (lateral view). Scale bars. $1.0 \mathrm{~mm}$ for A; $0.05 \mathrm{~mm}$ for $\mathrm{C}-\mathrm{G}$; $0.01 \mathrm{~mm}$ for $\mathrm{B}$.

compactly woven without open spaces in web, thin, with anterior margin thickly woven, having short distinct anterodorsal projection, and extending ventrolaterally; individual threads invisible or slightly visible; $3.5-4.2 \mathrm{~mm}$ long by $2.5-3.5 \mathrm{~mm}$ wide.

Mature larva. Body length $6.3-7.0 \mathrm{~mm}$. Body (Fig. 4A) creamy white, with distinct reddish-brown markings on abdomen; i.e., 4 dorsal spots on each of segments $2-7$ though all 4 spots on segment 2 usually very faintly visible or absent, and anterior 2 of 4 spots on segments 5-7 also often very faintly visible or absent; 1 lateral spot on each side of segments 1-4 though spot on segment 1 often very faintly visible or absent. Cephalic apotome (Fig. 5A) yellow, with posterior margin somewhat darkened in some larvae; head spots medium to dark brown, well defined. Lateral surface of head capsule (Fig. 5B) yellow, except eye-spot region white; eyebrow dark brown; 2 large spots posterior to eye-spot region and 1-3 small spots below eye-spot region clearly positive. Ventral surface of head capsule (Fig. 5C) yellow except medial portion widely darkened, and basal area on each side of postgenal cleft dark brown; horizontal and round spots on each side of postgenal cleft distinctively positive. Cervical sclerite composed of 2 small elliptical pieces, not fused to occiput, widely separated medially from each other. Antenna consisting of 3 segments and apical sensillum, much longer than stem of labral fan; proportional lengths of $1 \mathrm{st}, 2 \mathrm{nd}$, and $3 \mathrm{rd}$ segments 1.0 : $1.1-1.2: 0.8$. Labral fan with $26-32$ main rays. Mandible (Fig. 4B) with mandibular serrations consisting of 2 teeth (1 large and 1 small); large tooth making nearly right angle with mandible on apical side; comb-teeth composed of 3 teeth shortened from 1st to 3rd; supernumerary serrations absent. Hypostoma (Fig. 4C) with 9 apical teeth in row; median and corner teeth well developed; median tooth of 3 intermediate teeth on each side smallest; lateral serrations moderately developed apically; 4-6 hypostomal bristles lying slightly divergent posteriorly from lateral margin on each side. Postgenal cleft (Fig. 5C) small, 0.50-0.64 times as long as postgenal bridge, with anterior margin variable in shape, as shown in Fig. 4DF. Thoracic cuticle bare. Abdominal cuticle bare except both sides of anal sclerite moderately covered with simple colorless setae. Rectal scales present. Rectal organ (Fig. 4G) 

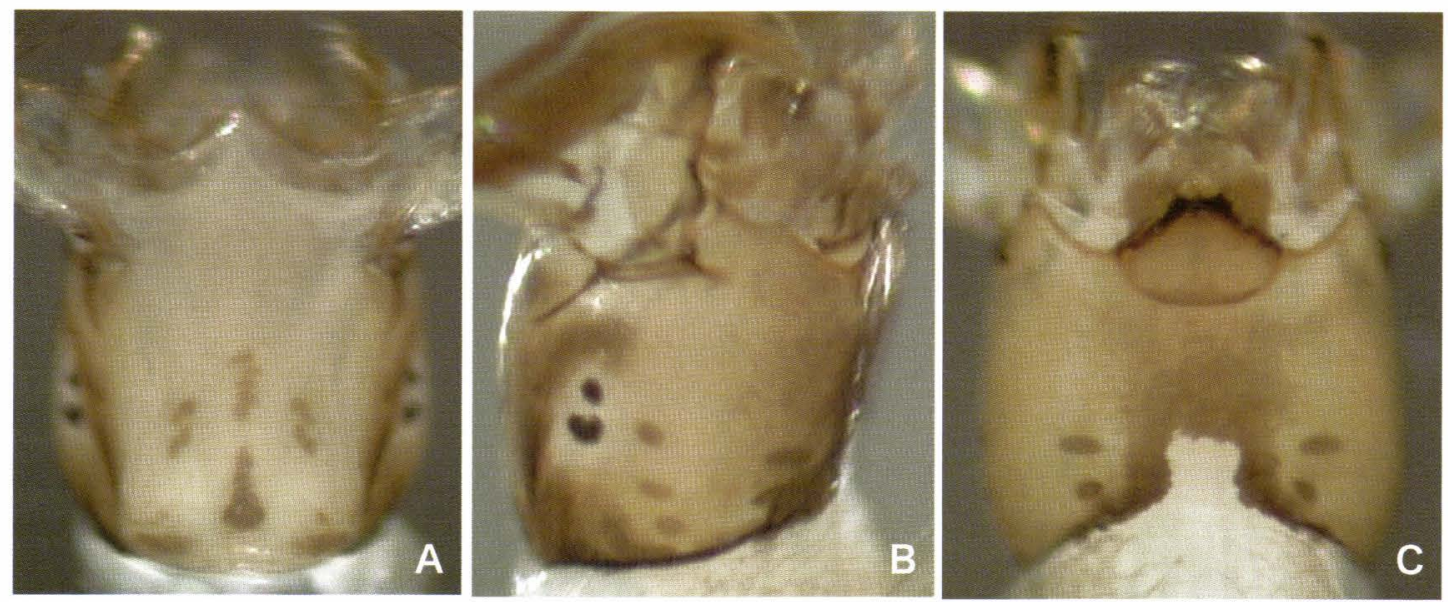

Fig. 5. Head capsules of mature larva of Simulium (Nevermannia) fangense sp. nov. A, dorsal view; B, lateral view; C, ventral view.

compound, with 17-21 long finger-like secondary lobules per lobe. Anal sclerite of usual $\mathrm{X}$-form, with anterior arms $0.7-0.8$ times as long as posterior ones, broadly sclerotized at basal juncture; sensilla absent on and just posterior to basal juncture area; accessory sclerite absent. Last abdominal segment much expanded ventrally forming large ventral papilla. Posterior circlet with $68-74$ rows of up to $12-$ 14 hooklets per row.

TYPE SPECIMENS. Holotype female (associated with pupal exuviae and cocoon), reared from pupa, collected from Doi Ang Khang, Fang District, Chiang Mai province, northern Thailand, 23.X.2005, by W. Choochote. Paratypes: 7 reared adults (3 females, 4 males), 1 pupa and 15 mature larvae, same data and date as those of holotype.

BIOLOGICAL NOTES. The pupae and larvae of $S$. (N.) fangense sp. nov. were found on leaves of trailing grasses and fallen leaves in a small stream (width 1.5$2.0 \mathrm{~m}$, depth $10-15 \mathrm{~cm}$, water temperature $19.0^{\circ} \mathrm{C}$, exposed to sun, altitude $1,400 \mathrm{~m}$ ) moderately flowing in a sparsely forested area. Associated species were S. (Gomphostilbia) asakoae Takaoka and Davies, $S$. (Simulium) lampangense Takaoka and Choochote, and S. (S.) sp. nr. chamlongi Takaoka and Suzuki.
DISTRIBUTION. Thailand.

ETYMOLOGY. The species name fangense refers to the name of the district, Fang, where this new species was collected.

REMARKS. Simulium (Nevermannia) fangense sp. nov. is readily assigned to the feuerborni species-group redefined by Takaoka (2003) by the combination of the following characters: male genitalia with a simple lamellate ventral plate (Fig. 2C), a short inwardly-twisted style (Fig. 2C, E), a simple narrow median sclerite (Fig. 2J) and several parameral hooks (Fig. 2K, L); the pupal gill with six long thread-like filaments per side (Fig. $3 \mathrm{~A}-\mathrm{E}$ ); and the larval head with a small short postgenal cleft (Fig. 5C).

Among the 19 other known species of the feuerborni species-group (Crosskey, 1999; Crosskey and Howard, 1997; Takaoka, 2001, 2003; Takaoka and Choochote, 2005; Takaoka and Saito, 2000, 2005), only four species, i.e., S. (N.) feuerborni Edwards from Indonesia (Edwards, 1934; Takaoka and Davies, 1996), Peninsular Malaysia (Takaoka and Davies, 1995) and Thailand (Kuvangkadilok et al., 1999), S. $(N$.) leigongshanense Chen and Zhang from China (Chen and Zhang, 1997), S. (N.) 
praelargum Datta from India (Datta, 1973), and S. (N.) sasai (Rubtsov) from Japan (Sato et al., 2005), have the cocoon with an anterodorsal projection like $S$. (N.) fangense sp. nov. Compared to these four known species, $S$. (N.) fangense sp. nov. is most similar to $S$. $(N$.) sasai (Rubtsov) in many features including the number of male large eye facets, the number of parameral hooks, and the arrangement of the pupal gill filaments, but is readily distinguished from the latter species in the female by the scutum medium brown with three longitudinal vittae (cf., brownishblack without longitudinal vittae in $S$. $(N$.) sasai), and in the larva by the larger size of the postgenal cleft relative to the postgenal bridge (0.50-0.64 versus $0.30-0.40$ ) and the greater number of secondary lobules per lobe (17-21 versus 5-10).

According to the redescription given by Takaoka and Davies (1996), S. (N.) feuerborni from Java differs from the present new species in the female by the fronshead ratio (i.e., $1: 5.4$ ), in the male by the smaller number of large eye facets in 15 vertical columns and in 17 or 18 horizontal rows and the smaller number of parameral hooks (three or four hooks), in the pupa by the arrangement of the gill filaments branching into $4+2$ filaments, and in the larva by the smaller postgenal cleft $0.37-0.43$ times as long as the postgenal bridge.

The four known species of the feuerborni species-group were described from adult males (and also females in one species) alone, and then, their pupal and larval stages have remained unknown. Among these, S. (N.) fuscinervis Edwards from Sabah has the paramere with 10 or 11 hooks (Edwards, 1933); S. (N.) bryopodium Delfinado from Palawan Island, Philippines, has the dark brown hind femur (Delfinado, 1971); S. (N.) senile Brunetti from West Himalaya bears the style with no apical spine (Brunetti, 1911); S. (N.) rufithorax Brunetti, described from a male and four females collected from India, has a reddish-brown thorax according to the original description (Brunetti, 1911).

\section{ACKNOWLEDGEMENTS}

We are grateful to Ms. Anuluck Junkum, Ms. Nathee Puangmalee, Mr. Pramote Suwanpait and Mr. Nirun Ittiponpanya, Department of Parasitology, Faculty of Medicine, Chiang Mai University, Chiang Mai, Thailand, for their assistance in field collections. We express our appreciation to Dr. Yasushi Otsuka, Department of Infectious Disease Control, Faculty of Medicine, Oita University, Oita, Japan, for his kind help in taking photographs of larval head capsules and making Figure 5. This work was supported in part by a Grant-in-Aid for Scientific Research (18406011) from the Japan Society for the Promotion of Science to H. T.

\section{REFERENCES}

Brunetti, E. 1911. New Oriental Nematocera. Rec. Indian Mus., 4: 259-316.

Chen, H. B. and Zhang, C. L. 1997. Two new species of Eusimulium from Guizhou province, China. Acta Zootaxonomica Sinica, 22: 301-306.

Crosskey, R. W. 1999. First Update to the Taxonomic and Geographical Inventory of World Blackflies (Diptera; Simuliidae). 10 pp., The Natur. Hist. Mus., London.

Crosskey, R. W. and Howard, T. M. 1997. A New Taxonomic and Geographical Inventory of World Blackflies (Diptera: Simuliidae). 144 pp., The Natur. Hist. Mus., London.

Datta, M. 1973. New species of black flies (Diptera: Simuliidae) of the subgenera Eusimulium Roubaud and Gomphostilbia Enderlein from Darjeeling area, India. Orient. Insects, 7: 363-402.

Delfinado, M. D. 1971. Some Simuliidae and Curtonotidae from the Philippines and the Bismarck Islands (Insecta, Diptera). Steenstrupia, 1: 131-139.

Edwards, F. W. 1933. Diptera Nematocera from Mount Kinabalu. J. Fed. Malay States Mus., 17: 223-296.

Edwards, F. W. 1934. The Simuliidae (Diptera) of Java and Sumatra. Arch. f. Hydrobiol., 13, Suppl. "Tropische Binnengewässer" 5: 92-138. 
Kuvangkadilok, C., Phayuhasena, S. and Baimai, V. 1999. Population genetic studies on Simulium feuerborni Edwards (Diptera: Simuliidae) from northern Thailand. Genome, 42: 80-86.

Sato, H., Saito, K. and Takaoka, H. 2005. Revised description of Simulium (Nevermannia) sasai, a rare and poorly known species in Japan (Diptera: Simuliidae). Med. Entomol. Zool., 56: 299-307.

Takaoka, H. 2001. Two new and three newly recorded species of black flies (Diptera: Simuliidae) from Sabah, Malaysia. Jpn. J. Trop. Med. Hyg., 29: 221-230.

Takaoka, H. 2003. The Black Flies (Diptera: Simuliidae) of Sulawesi, Maluku and Irian Jaya. xxii +581 pp., Kyushu University Press, Fukuoka.

Takaoka, H. and Choochote, W. 2005. Two new species of Simulium (Nevermannia) (Diptera: Simulii- dae) from northern Thailand. Trop. Med. Health, 33: 133-141.

Takaoka, H. and Davies, D. M. 1995. The Black Flies (Diptera: Simuliidae) of West Malaysia. viii +175 pp., Kyushu University Press, Fukuoka.

Takaoka, H. and Davies, D. M. 1996. The Black Flies (Diptera: Simuliidae) of Java, Indonesia. viii +81 pp., Bishop Mus. Bull. Entomol. 6, Bishop Museum Press, Hawaii.

Takaoka, H. and Saito, K. 2000. Description of a new species of Simulium (Nevermannia) from Japan (Diptera: Simuliidae). Jpn. J. Trop. Med. Hyg., 28: 19-24.

Takaoka, H. and Saito, K. 2005. A new species of Simulium (Nevermannia) from Izu Islands, Japan (Diptera: Simuliidae). Med. Entomol. Zool., 56: 309317. 